\title{
Schema or not schema? that could be the question of teacher
}

\author{
Damien Givry* \\ ESPE, Aix Marseille Université \\ E-mail: damien.givryeuniv-amu.fr
}

\begin{abstract}
This research focuses on written language and systems of signs to study the learning of scientific concepts [1]. It proposes to show that students (Grade 10 [aged 15]) mobilize ideas about gas in different ways in regard to the semiotic registers (text or diagram) proposed during an assessment. Our study adopts a socio-constructivist approach of learning and develops a theoretical framework, articulating elements from the didactic of physics with semiotics concepts of Duval [2]. We give a test with questions (using simultaneously text and diagram) to approximately 90 students just after a teaching sequence on gas. We categorize with the software Sphinx students' answers and diagram. This analysis has excellent intra-analyst reliability of our coding with the best level of reproducibility (Cohen's Kappa test) and all our results are statistically significant (test of Khi2). Our results show that: (I) situations affect the mobilization of students' ideas in regard to the semiotics registers involved in the assessment, (II) the semiotics registers have an effect on the mobilization of students' ideas according to the facets of knowledge. Students are much more efficient in the register of: (a) schema to use facets about particles contained in gas and it homogeneous distribution and (b) text to mobilize their ideas about the action of gas, (III) the semiotic registers used in the tasks of the teaching sequence on gas could possibly be related to the mobilization of students' ideas in the semiotics registers involved during the assessment. The implications of this work in teaching and research in didactic of physic are important. It allows to have a better consideration of the semiotic register to assess students' knowledge.
\end{abstract}

References

[1] J. L., Lemke, Multiplying Meaning: Visual and Verbal Semiotics in Scientific Text, In J. R. Martin \& R. Veel (Éd.), Reading Science, Routledge : London (1998)

[2] R, Duval . Sémiosis et pensée humaine: registres sémiotiques et apprentissages intellectuels.

Peter Lang : Neuchatel (Suisse) (1995)

Frontiers of Fundamental Physics 14 - FFP14,

15-18 July 2014

Aix Marseille University (AMU) Saint-Charles Campus, Marseille

${ }^{*}$ Speaker. 